\title{
Tranexamic acid and early saphenous vein graft patency in conventional coronary artery bypass graft surgery: A prospective randomized controlled clinical trial
}

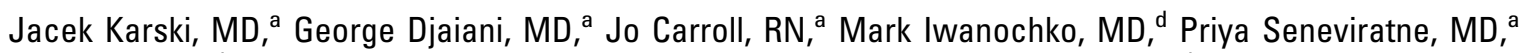

Peter Liu, MD, ${ }^{\mathrm{d}}$ Walter Kucharczyk, MD, ${ }^{\mathrm{c}}$ Ludwik Fedorko, MD, ${ }^{\mathrm{a}}$ Tirone David, MD, ${ }^{\mathrm{b}}$ and Davy Cheng, MD

From the Department of Anesthesia, ${ }^{\text {a }}$ Division of Cardiac Surgery, , Department of Medical Imaging, ${ }^{\mathrm{c}}$ and Department of Cardiology, ${ }^{\mathrm{d}}$ Toronto General Hospital, University Health Network, University of Toronto, Toronto, Ontario, Canada.

Supported by a Pharmacia Canada Educational Grant.

Received for publication July 21, 2004; revisions received Nov 3, 2004; accepted for publication Nov 5, 2004.

Address for reprints: Jacek Karski, MD, FRCPC, Department of Anesthesia, Toronto General Hospital, 200 Elizabeth St, 3EN-400, Toronto, Ontario M5G 2C4, Canada (E-mail: jacek.karski@uhn.on.ca).

J Thorac Cardiovasc Surg 2005;130:309-14

$0022-5223 / \$ 30.00$

Copyright (c) 2005 by The American Association for Thoracic Surgery

doi:10.1016/j.jtcvs.2004.11.015
Objective: Use of antifibrinolytic agents reduces the risk of bleeding and decreases the need for blood product use in patients undergoing cardiac surgery. The purpose of this study was to determine whether perioperative use of tranexamic acid decreases the rate of saphenous vein graft patency in the early postoperative period after conventional coronary artery bypass grafting surgery.

Methods: A total of 312 patients scheduled for elective coronary artery bypass grafting surgery with cardiopulmonary bypass were randomized to receive either tranexamic acid $100 \mathrm{mg} / \mathrm{kg}(\mathrm{n}=147)$ or placebo $(\mathrm{n}=165)$ in a double-blinded fashion before the initiation of cardiopulmonary bypass. Saphenous vein graft patency was assessed with magnetic resonance imaging 5 to 30 days after surgery.

Results: Both groups were comparable with respect to baseline demographic data and surgical characteristics. A total of $237(76 \%)$ patients underwent magnetic resonance imaging assessment. A total of 297 saphenous vein grafts were performed and 253 (85.2\%; 95\% confidence interval, 83.5\%-86.9\%) were seen in the tranexamic acid group, and 265 saphenous vein grafts were performed and $231(87.2 \%$; 95\% confidence interval, $85.5 \%-88.9 \%)$ were seen in the placebo group $(P=.4969)$. The blood loss and blood product transfusion rates in the tranexamic acid group were significantly lower than in the placebo group. There was no difference between groups with respect to postoperative morbidity and mortality.

Conclusions: The administration of tranexamic acid before cardiopulmonary bypass did not seem to compromise early venous graft patency rates but reduced perioperative blood product transfusion rates. Consequently, tranexamic acid could be advocated for routine use in patients undergoing conventional coronary artery bypass grafting surgery.

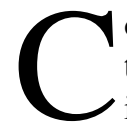
oronary revascularization surgery is increasingly performed on older patients (>65 years) with extensive coronary artery pathology who have impaired left ventricular function, decreased physiological reserve, and multiple comorbid conditions. ${ }^{1-3}$ It is estimated that approximately half a million patients undergo cardiac surgical procedures in the United States annually: this costs approximately $\$ 9$ billion per year. The increase in resource utilization and healthcare costs has resulted in changing health-care practices to maximize cost containment and in efficient resource utilization by widespread adoption of fast-track cardiac surgery pathways. ${ }^{4}$

Postoperative hemostasis is an integral part of a fast-tracking process to reduce the exposure of patients to blood transfusion-related complications and decrease heavy demands on blood-bank resources. ${ }^{5-7}$ The use of antifibrinolytic agents before 
the initiation of cardiopulmonary bypass (CPB) reduces perioperative bleeding and has been shown to be a costeffective way to reduce the need for blood products. ${ }^{8-15}$ Nevertheless, perioperative inhibition of fibrinolysis may increase the rate of early graft occlusion rates, thus precluding its routine use in patients undergoing coronary revascularization procedures. Concerns have been expressed regarding the use of a natural serine proteinase inhibitor, aprotinin, and saphenous vein graft (SVG) thrombosis after cardiac surgery. A recent report from the International Multicenter Aprotinin Graft Patency Experience trial demonstrated a significant increase in early SVG occlusion rates in aprotinin-treated patients when compared with placebo. ${ }^{16}$ Furthermore, the current cost of aprotinin prevents its routine use in many institutions that identify more cost-effective alternatives, such as the synthetic lysine analogs tranexamic acid (TA) and $\varepsilon$-aminocaproic acid. The current cost of aprotinin and TA in our institution is \$1348CAD and $\$ 147$ CAD per case, respectively. Although TA is more economical, there is currently no evidence to support our contention that TA can be used safely without compromising coronary graft patency. The purpose of this study was to determine whether the perioperative use of TA decreases early SVG patency rates after coronary artery bypass grafting (CABG) surgery.

\section{Methods}

\section{Study Population}

After institutional review board approval, informed consent was obtained from 312 patients scheduled for elective CABG surgery with CPB. Patients with a history of claustrophobia; known contraindications to magnetic resonance imaging (MRI); bleeding disorders; preoperative hemoglobin less than $135 \mathrm{~g} / \mathrm{L}$; symptomatic peripheral vascular disease; connective tissue disease; age older than 80 years; impaired renal function (creatinine $>2.0$ $\mathrm{mg} / \mathrm{dL}$ ); active liver disease; known allergies to TA, aspirin, or contrast dye (Omnipaque; Sterling Winthrop, Inc, Collegeville, $\mathrm{Pa}$ ); or left ventricular function ejection fraction less than $20 \%$ were excluded from the study.

\section{Description of Management Strategies}

A computer-generated randomization code in blocks of 4 was used to assign patients to receive either TA or placebo in a doubleblinded fashion. The hospital pharmacy department prepared identical bags of $100-\mathrm{mL}$ solution containing either TA $100 \mathrm{mg} / \mathrm{kg}$ or $5 \%$ dextrose (placebo), which was administered intravenously over 20 minutes after the induction of anesthesia.

All routine cardiac medications were continued up to the morning of the operation. All patients received premedication with lorazepam $2 \mathrm{mg} 1$ to 2 hours before the operation. The anesthetic technique was standardized to include fentanyl $(10-20 \mu \mathrm{g} / \mathrm{kg})$, midazolam $(0.1 \mathrm{mg} / \mathrm{kg})$, pancuronium $(0.15-0.20 \mathrm{mg} / \mathrm{kg})$, and isoflurane $(0.5 \%-1.5 \%)$. The initial dose of heparin was $300 \mathrm{U} / \mathrm{kg}$. Additional heparin was given as necessary to maintain activated clotting time greater than 400 seconds. Monitoring included continuous direct arterial blood pressure, central venous pressure, pulmonary artery catheter, electrocardiography (leads II and V) with continuous ST-segment analysis, pulse oximetry, capnography, and nasopharyngeal temperature measurements.

All patients were operated on by the same team of surgeons at Toronto General Hospital. Patients underwent median sternotomy with harvesting of the saphenous veins and internal thoracic arteries (ITAs) as conduits. Myocardial protection was achieved with intermittent antegrade and often retrograde cold-blood cardioplegia. Management of CPB included systemic temperature drift to $33^{\circ} \mathrm{C}$, alpha-stat $\mathrm{pH}$ management, mean perfusion pressure between 50 and $90 \mathrm{~mm} \mathrm{Hg}$, pump flow rates of 2.0 to 2.4 $\mathrm{L} \cdot \min ^{-1} \cdot \mathrm{m}^{-2}$, and hematocrit greater than $20 \%$. Before separation from $\mathrm{CPB}$, patients were rewarmed to $37^{\circ} \mathrm{C}$. After separation from CPB, heparin was neutralized with protamine $1 \mathrm{mg} / 100$ $\mathrm{U}$ of heparin. After surgery, patients were transferred to the intensive care unit for postoperative ventilation. Sedation was achieved with propofol infusion $\left(0.5-4 \mathrm{mg} \cdot \mathrm{kg}^{-1} \cdot \mathrm{h}^{-1}\right)$ and morphine boluses. Patients were extubated according to the following criteria: patient responsive and cooperative, arterial oxygen saturation $94 \%$ or more with fraction of inspired oxygen $60 \%$ or less, complete reversal of neuromuscular blockade, $\mathrm{PaCO}_{2} 35$ to $55 \mathrm{~mm}$ $\mathrm{Hg}$, stable hemodynamics, absence of uncontrolled arrhythmia, and nasopharyngeal temperature greater than $36^{\circ} \mathrm{C}$.

If the postoperative mediastinal chest tube drainage was 300 $\mathrm{mL} / \mathrm{h}$ or more despite the standard therapeutic measures, the staff hematologist was consulted with respect to the administration of open-labeled TA $100 \mathrm{mg} / \mathrm{kg}$ without breaking the randomization code, regardless of the patient group assignment.

\section{Coronary MRI}

Cine MRI of SVG patency assessment was performed between 5 and 30 days after surgery. After localizing spin-echo coronal images were obtained, multiple axial multisliced interleaved cine MRI acquisition was performed; each consisted of two to four 5to $10-\mathrm{mm}$ slices. Eight to 24 frames per cardiac cycle were obtained from the superior main pulmonary artery to the inferior left ventricle. Images were transferred to the film and read by an independent observer without knowledge of the treatment group but with knowledge of the original graft insertion. Graft patency was defined by the presence of a bright graft flow signal not corresponding to the normal vessels and identified on multiple frames at multiple levels separating the great vessels and the epicardial surface of the heart.

\section{Statistical Analysis}

Comparability of both groups was tested with the use of $\chi^{2}$ statistics on qualitative variables and 1-way analysis of variance on quantitative variables. The primary outcome of graft patency was analyzed with a $2 \times 2$ contingency table, which included 2 possible outcomes: the grafts seen or not seen by the MRI. Confidence intervals for proportions were calculated at $95 \%$. A $P$ value less than .05 was considered significant. All analyses were performed on an intention-to-treat basis. Statistical analysis was conducted with SPSS computer software (SPSS Inc, Chicago, Ill).

\section{Results}

A total of 312 patients were randomized according to a computer-generated randomization code: 147 patients in the 
TABLE 1. Demographic variables and operative characteristics

\begin{tabular}{|c|c|c|}
\hline Baseline characteristic & $\begin{array}{l}\text { TA group } \\
(n=147)\end{array}$ & $\begin{array}{l}\text { Placebo group } \\
\quad(n=165)\end{array}$ \\
\hline Age, y (mean \pm SD) & $59.9 \pm 8.9$ & $60.0 \pm 8.3$ \\
\hline Weight, kg (mean \pm SD) & $79.8 \pm 12.0$ & $81.6 \pm 12.0$ \\
\hline Male, $\mathrm{n}(\%)$ & $128(87.0)$ & $147(89.0)$ \\
\hline $\mathrm{BSA}, \mathrm{m}^{2}($ mean $\pm \mathrm{SD})$ & $1.92 \pm 0.18$ & $1.95 \pm 0.18$ \\
\hline $\mathrm{EF}<40 \%, \mathrm{n}(\%)$ & $32(22.0)$ & $40(24.0)$ \\
\hline \multicolumn{3}{|l|}{ Coexisting illness, n (\%) } \\
\hline Hypertension & $77(53.1)$ & $90(56.3)$ \\
\hline Myocardial infarction & $71(48.3)$ & $81(49.4)$ \\
\hline Diabetes & $41(27.9)$ & $52(31.5)$ \\
\hline Peripheral vascular disease & $43(29.4)$ & $42(25.9)$ \\
\hline Stroke & $3(2.0)$ & $7(4.3)$ \\
\hline \multicolumn{3}{|l|}{ Preoperative medication, $\mathrm{n}(\%)$} \\
\hline$\beta$-Blockers & $82(56.2)$ & $78(47.3)$ \\
\hline Calcium channel blockers & 66 (47.3) & $66(40.0)$ \\
\hline Aspirin & $118(80.8)$ & $130(81.8)$ \\
\hline NSAID & $2(1.4)$ & $2(1.2)$ \\
\hline \multicolumn{3}{|l|}{$\begin{array}{l}\text { Preoperative laboratory } \\
\quad \text { variables (mean } \pm S D \text { ) }\end{array}$} \\
\hline PTT (s) & $31.0 \pm 23.2$ & $32.1 \pm 16.0$ \\
\hline PT (s) & $10.9 \pm 1.1$ & $11.1 \pm 1.4$ \\
\hline Hemoglobin $(\mathrm{g} / \mathrm{dL})$ & $141.2 \pm 11.7$ & $143.7 \pm 11.6$ \\
\hline Platelet count $\left(10^{3} / \mathrm{mm}^{3}\right)$ & $223 \pm 58$ & $229 \pm 55$ \\
\hline Creatinine $(\mathrm{mg} / \mathrm{dL})$ & $93.1 \pm 16.8$ & $92.4 \pm 19.7$ \\
\hline \multicolumn{3}{|l|}{$\begin{array}{l}\text { Intraoperative variables (mean } \\
\quad \pm \text { SD) }\end{array}$} \\
\hline CPB time (min) & $80.7 \pm 29.9$ & $82.0 \pm 20.0$ \\
\hline $\begin{array}{l}\text { Minimum CPB temperature } \\
\left({ }^{\circ} \mathrm{C}\right)\end{array}$ & $33.5 \pm 1.1$ & $33.4 \pm 1.2$ \\
\hline $\begin{array}{l}\text { Saphenous vein grafts, } n \\
\quad(\text { mean } \pm S D)\end{array}$ & $2.7 \pm 0.7$ & $2.8 \pm 0.7$ \\
\hline LITA grafts $(\%)$ & 97.2 & 100 \\
\hline Total heparin, $U$ (mean $\pm S D)$ & $39,225 \pm 12,903$ & $37,558 \pm 12,874$ \\
\hline $\begin{array}{l}\text { Total protamine, mg (mean } \pm \\
\text { SD) }\end{array}$ & $406.9 \pm 106.5$ & $405.0 \pm 118.3$ \\
\hline
\end{tabular}

$\overline{T A}$, Tranexamic acid; $B S A$, body surface area; $E F$, ejection fraction; NSAID, nonsteroidal anti-inflammatory drug; $P T T$, partial thromboplastin time; $P T$, prothrombin time; $C P B$, cardiopulmonary bypass; $L I T A$, left internal thoracic artery.

TA group and 165 patients in the placebo group. There were no differences in the baseline demographic data or surgical characteristics between groups (Table 1). None of the patients received aspirin or other antiplatelet agents within 7 days of the operation. Open-labeled TA was administered to 4 patients in the TA group and 24 patients in the placebo group in the postoperative period. A total of 237 (76\%) patients underwent MRI assessment for graft patency. MRI was not performed in 29 patients from the TA group and 45 patients from the placebo group $(P=.11)$. The reasons for MRI cancellation included death, stroke, presence of pacing
TABLE 2. Magnetic resonance imaging (MRI) assessment of saphenous vein graft patency

\begin{tabular}{lcc}
\hline Variable & $\begin{array}{c}\text { TA group } \\
\text { (n= 118) }\end{array}$ & $\begin{array}{c}\text { Placebo group } \\
(\mathbf{n}=\mathbf{1 1 9})\end{array}$ \\
\hline No. grafts performed & 297 & 265 \\
Grafts seen on MRI, n (\%) & $253(85.2)$ & $231(87.2)$ \\
{$[95 \% \mathrm{CI}]$} & {$[83.5-86.9]$} & {$[85.5-88.9]$} \\
Grafts not seen on MRI, n (\%) & $44(14.8)$ & $34(12.8)$ \\
{$[95 \% \mathrm{Cl}]$} & {$[13.1-16.5]$} & {$[11.1-14.6]$}
\end{tabular}

$T A$, Tranexamic acid; $\mathrm{Cl}$, confidence interval.

wires at a time of MRI-allocated time, claustrophobia, and patient refusal.

There was no significant difference with respect to early SVG patency between the 2 groups (Table 2; $P=.4969$ ). The confidence intervals for a test group were estimated by using the binomial distribution. Because of the large sample size within each test population, the normal approximation was used. The binomial confidence limits were approximately $1.7 \%$ for each of the classes. The $95 \%$ confidence interval of the placebo group was $85.5 \%$ to $88.9 \%$, and the 95\% confidence interval of TA group was $83.5 \%$ to $86.9 \%$. The null hypothesis of the test would have been rejected if fewer than 240 or more than 274 graphs had been seen in the TA group (Table 2). On the basis of the small confidence interval $( \pm 1.7 \%)$, it was concluded that the test was sufficiently powerful to detect a difference between the 2 groups if one truly existed.

Chest tube drainage was significantly reduced in the TA group at 6,12, and 24 hours after surgery (Figure 1). This reduction resulted in decreased requirements for blood product transfusion in the TA group when compared with placebo. Packed red blood cells were transfused in $16 \%$ versus $25 \%(P=.037)$, fresh frozen plasma was transfused in $1.4 \%$ versus $7.3 \%(P=.011)$, and platelets were transfused in $0.7 \%$ versus $3.6 \%(P=.08)$ of patients in the TA and placebo groups, respectively. One $(0.7 \%)$ patient in the TA group and $15(9.0 \%)$ patients in the placebo group had excessive chest tube drainage $(>750 \mathrm{~mL}$ over the first 6 hours after surgery; $P=.001$ ). The proportion of patients receiving open-label TA was lower in the TA group than in the placebo group $(2.8 \%$ vs $14.6 \% ; P=.001)$. There was no difference between groups with respect to postoperative morbidity and mortality (Table 3 ).

\section{Discussion}

In this study, we have shown for the first time that early SVG patency is not compromised by the perioperative use of the synthetic lysine analog TA. Induction of the fibrinolytic system is advocated as one of the major components of perioperative coagulopathy. ${ }^{17}$ Perioperative use of antifi- 


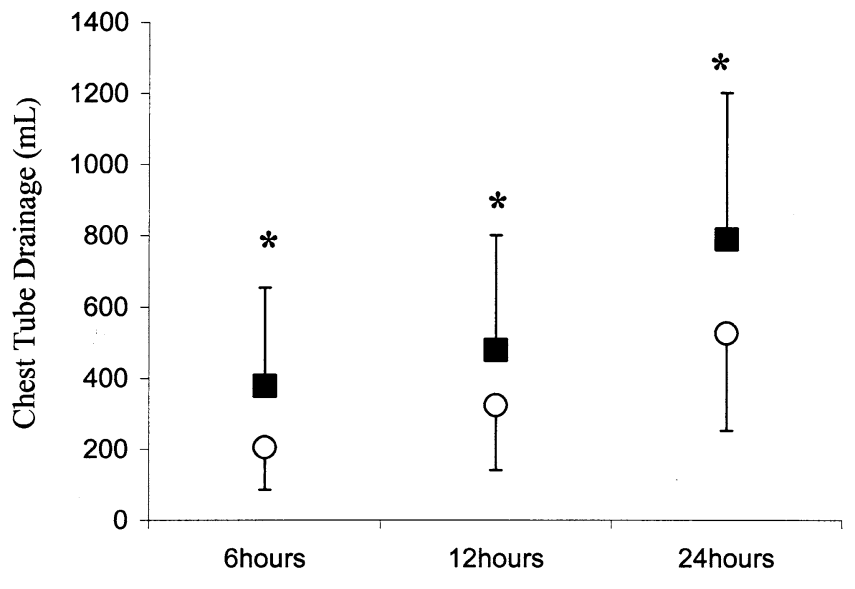

Postoperative Period

Figure 1. Postoperative chest tube drainage at 3 consecutive time periods. Data analyzed with Mann-Whitney test and shown in the figure as mean and SD. ${ }^{*} \boldsymbol{P}<.0001$. $\bigcirc$, Tranexamic acid; $\boldsymbol{\square}$, placebo.

brinolytic agents considerably reduces postoperative blood loss and blood product requirements after cardiac surgery. ${ }^{13,18,19}$ Previously, we ${ }^{13}$ showed that the use of TA during elective $\mathrm{CABG}$ surgery reduced the proportion of patients with a 6-hour postoperative blood loss in excess of $750 \mathrm{~mL}$ from $18 \%$ to $2 \%$. Furthermore, in a dose-escalating study, we identified that TA $100 \mathrm{mg} / \mathrm{kg}$ seemed to be an optimal dose to achieve this goal. ${ }^{14}$ Consequently, this dose was chosen in our current study. This study confirmed our previous findings that TA considerably reduced postoperative bleeding and, consequently, blood product transfusion rates, thus minimizing the risks of allogeneic blood transfusion and resulting in potential overall cost reduction.

The main concern with the administration of antifibrinolytic agents during the perioperative period remains reduced coronary bypass graft patency and other thrombotic complications. The standard by which the operative results must be judged is high. It is well known that the early patency rate for ITA anastomoses completed with standard techniques is greater than $94 \%{ }^{20,21}$ However, vein graft patency rates do not fare so well. Even without the use of antifibrinolytic agents, $5 \%$ to $15 \%$ of all grafts may occlude in the early postoperative period, with a possible recurrence of myocardial ischemia, infarction, or even death. ${ }^{22,23}$ Furthermore, SVG patency at 1 year after CABG surgery varies from $77 \%$ to $88 \%$. $^{21,24}$

Extensive work has been performed to investigate the safety aspects of aprotinin and early graft occlusion after CABG surgery. A multicenter International Multicenter Aprotinin Graft Patency Experience trial evaluated 870 pri-
TABLE 3. Postoperative complications

\begin{tabular}{lcc}
\hline Complication & $\begin{array}{c}\text { TA group } \\
\text { (n = 147) }\end{array}$ & $\begin{array}{c}\text { Placebo group } \\
\text { (n }=\mathbf{1 6 5})\end{array}$ \\
\hline Atrial fibrillation & $22(14.9)$ & $23(13.9)$ \\
Cardiac arrest & $3(2.0)$ & $1(0.6)$ \\
Myocardial infarction & $2(1.4)$ & $3(1.8)$ \\
Stroke & $1(0.68)$ & $1(0.6)$ \\
Death & $3(2.0)$ & $1(0.6)$
\end{tabular}

Data are expressed as absolute number (\%). TA, Tranexamic acid.

mary $\mathrm{CABG}$ patients randomized to receive either aprotinin or placebo. Coronary graft occlusion rates were evaluated by postoperative angiography. There was a significant increase in early graft occlusion rates in aprotinin-treated patients: $15.4 \%$ versus $10.9 \%$ in the placebo group. Moreover, in some participating sites, early SVG occlusion rates were as high as $23 \%$ in the aprotinin group, compared with $12.4 \%$ in the placebo group. However, there was no difference in mortality and myocardial infarction rates between the 2 groups despite sufficient power of the study to detect such a difference. ${ }^{16}$

Although coronary angiography is still considered a gold standard in the assessment of graft patency after coronary revascularization surgery, this technique uses intra-arterial catheterization and injections of contrast medium, with significant $\mathrm{x}$-ray exposure and potential complications. ${ }^{25,26}$ Recent advances in magnetic resonance coronary angiography have made it a suitable method for visualizing coronary arteries-and, particularly, venous grafts, which are larger in diameter-in a way that is less invasive and expensive than conventional angiography. ${ }^{27,28}$ The cardiovascular MRI provides accurate and highly reproducible tomographic images in any desired anatomic plane and is not limited by acoustic windows. It is a safe and noninvasive method with no risk of ionizing radiation that provides accurate information on cardiac structures, blood flow, and angiography. Several studies have investigated the sensitivity and specificity of MRI in assessing graft patency after CABG surgery. White and colleagues ${ }^{29}$ found a $78 \%$ predictive accuracy of MRI in determining the graft patency in 25 patients ( 72 grafts) after CABG surgery. Rubinstein and colleagues $^{30}$ studied 20 patients (47 grafts) by using MRI versus cardiac catheterization. The reported sensitivity and specificity of MRI were $92 \%$ and $85 \%$, respectively. ${ }^{30}$ A similar study was conducted by Aurigemma and associates, ${ }^{31}$ who analyzed data from 20 patients (40 grafts) by using cine MRI and found that the sensitivity and specificity of MRI were $88 \%$ and $100 \%$, respectively, when compared with conventional cardiac catheterization. More recently, Langerak and associates ${ }^{32}$ described high-resolution magnetic resonance angiography for de- 
tection of vein graft disease in patients who presented with recurrent chest pain after bypass surgery. There was good agreement between MRI and coronary angiography for identifying both graft occlusion and graft stenosis, and the MRI images were judged insufficient in only $10 \%$ of grafts. ${ }^{32}$ Although at present the MRI has not completely replaced conventional coronary angiography, future developments in magnetic resonance technology will increase the sensitivity of current methods for assessing the severity of coronary artery disease, as well as for guiding surgical revascularization and determining graft patency after surgery.

The primary objective of this study was to determine the equivalency of SVG patency rates between the treatment and placebo groups. Because of the limitations of MRI software, this study could not determine the overall SVG patency rates after surgery. However, our results showed insignificant variation in graft patency rates between the 2 groups, and the actual SVG patency rates could have been higher only if all constructed grafts had been seen on MRI. Another limitation of this study relates to lack of assessment of arterial graft patency. However, to measure ITA graft patency rates, our sample size would have to be considerably increased. Each patient received on average 1 ITA graft and 2 to 3 SVGs; consequently, if one were to estimate ITA graft patency, the sample size would need to be calculated on the basis of the number of patients participating in the study, rather than on the number of grafts performed. Within this study design, we could only speculate that ITA graft patency rates were comparable in both groups of patients on the basis of similar rates of postoperative cardiac complications.

In conclusion, our study has demonstrated that the synthetic lysine analog TA did not seem to compromise SVG patency rates. TA could be advocated for routine use in patients undergoing coronary revascularization procedures with CPB to minimize postoperative bleeding and reduce perioperative blood product transfusion rates.

We thank the cardiac anesthesiologists, cardiac surgeons, and nurses of the Cardiovascular Intensive Care Unit at Toronto General Hospital.

\section{References}

1. Ivanov J, Weisel RD, David TE, Naylor CD. Fifteen-year trends in risk severity and operative mortality in elderly patients undergoing coronary artery bypass graft surgery. Circulation. 1998;97:673-80.

2. Christakis GT, Ivanov J, Weisel RD, Birnbaum PL, David TE, Salerno TA. The changing pattern of coronary artery bypass surgery. Circulation. 1989;80:I151-61.

3. Jones EL, Weintraub WS, Craver JM, Guyton RA, Cohen CL. Coronary bypass surgery: is the operation different today? J Thorac Cardiovasc Surg. 1991;101:108-15.

4. Cheng DC. Fast track cardiac surgery pathways: early extubation, process of care, and cost containment. Anesthesiology. 1998;88:1429-33.
5. Ferraris VA, Gildengorin V. Predictors of excessive blood use after coronary artery bypass grafting. A multivariate analysis. Surgery. 1989;4:492-7.

6. Mammen EF, Koets MH, Washington BC, Wolk LW, Brown JM, Burdick M, et al. Hemostasis changes during cardiopulmonary bypass surgery. Semin Thromb Hemost. 1985;11:281-92.

7. Bove JR. Transfusion associated hepatitis and AIDS. N Engl J Med. 1987;317:242-6

8. Horrow JC, Hlavacek J, Strong MD, Collier W, Brodsky I, Goldman SM, et al. Prophylactic tranexamic acid decreases bleeding after cardiac operations. J Thorac Cardiovasc Surg. 1990;99:70-4.

9. Horrow JC, Van Riper DF, Strong MD, Brodsky I, Parmet JL. Haemostatic effects of tranexamic acid and desmopressin during cardiac surgery. Circulation. 1991;85:2063-70.

10. Vander Salm TJ, Ansell JE, Okike ON, Marsicano TH, Lew R, Stephenson WP, et al. The role of epsilon-aminocaproic acid in reducing bleeding after cardiac operation: a double-blind randomized study. J Thorac Cardiovasc Surg. 1988;95:538-40.

11. van Oeveren W, Harder MP, Roozendaal KJ, Eijsman L, Wildevuur CR. Aprotinin protects platelets against the initial effect of cardiopulmonary bypass. J Thorac Cardiovasc Surg. 1990;99:788-96.

12. Karski JM, Teasdale SJ, Norman PH, Carroll JA, Weisel RD, Glynn MF. Prevention of postbypass bleeding with tranexamic acid and epsilon-aminocaproic acid. J Cardiothorac Vasc Anesth. 1993;7: 431-5.

13. Karski JM, Teasdale SJ, Norman P, Carroll J, VanKessel K, Wong P, et al. Prevention of bleeding after cardiopulmonary bypass with highdose tranexamic acid. Double-blind, randomized clinical trial. $J$ Thorac Cardiovasc Surg. 1995;110:835-42.

14. Karski JM, Dowd NP, Joiner R, Carroll J, Peniston C, Bailey K, et al. The effect of three different doses of tranexamic acid on blood loss after cardiac surgery with mild systemic hypothermia (32 degrees C). J Cardiothorac Vasc Anesth. 1998;12:642-6.

15. Smith PK, Datta SK, Muhlbaier LH, Samsa G, Nadel A, Lipscomb J. Cost analysis of aprotinin for coronary artery bypass patients: analysis of the randomized trials. Ann Thorac Surg. 2004;77:635-42.

16. Alderman EL, Levy JH, Rich JB, Nili M, Vidne B, Schaff H, et al. Analyses of coronary graft patency after aprotinin use: results from the International Multicenter Aprotinin Graft Patency Experience (IMAGE) trial. J Thorac Cardiovasc Surg. 1998;116:716-30.

17. de Haan J, Schonberger J, Haan J, van Oeveren W, Eijgelaar A. Tissue-type plasminogen activator and fibrin monomers synergistically cause platelet dysfunction during retransfusion of shed blood after cardiopulmonary bypass. J Thorac Cardiovasc Surg. 1993;106: 1017-23.

18. Brown RS, Thwaites BK, Mongan PD. Tranexamic acid is effective in decreasing postoperative bleeding and transfusions in primary coronary artery bypass operations: a double-blind, randomized, placebocontrolled trial. Anesth Analg. 1997;85:963-70.

19. Levy JH. Pharmacologic preservation of the hemostatic system during cardiac surgery. Ann Thorac Surg. 2001;72:S1814-20.

20. Gill IS, FitzGibbon GM, Higginson LAJ, Valji A, Keon WJ. Minimally invasive coronary artery bypass. Ann Thorac Surg. 1997;64: 710-4.

21. Grondin CM, Campeau L, Lesperance J, Enjalbert M, Bourassa MG. Comparison of late changes in internal mammary artery and saphenous vein grafts in two consecutive series of patients 10 years after operation. Circulation. 1984;70(suppl 1):1208-12.

22. Chesebro JH, Lam JY, Fuster V. The pathogenesis and prevention of aortocoronary vein bypass graft occlusion and restenosis after arterial angioplasty: role of vascular injury and platelet thrombus deposition. J Am Coll Cardiol. 1986;8:57B-66B.

23. Bourassa MG. Fate of venous grafts: the past, the present and the future. J Am Coll Cardiol. 1991;17:1081-3.

24. Barner HB, Mudd JG, Mark AL, Ahmad N, Dickens JF. Patency of internal mammary-coronary grafts. Circulation. 1976;54(suppl 3):70-3.

25. Davis K, Kennedy JW, Kemp HG, Judkins MP, Gosselin AJ, Killip T. Complications of coronary arteriography from the collaborative study of coronary artery surgery (CASS). Circulation. 1979;59:1105-12. 
26. Kennedy JW, Baxley WA, Bunnell IL, Gensisni GG, Messer JV, Mudd JG, et al. Mortality related to cardiac catheterisation and angiography. Cathet Cardiovasc Diagn. 1982;8:323-40.

27. Hardy CJ, Darrow RD, Pauly JM, Kerr AB, Dumoulin CL, Hu BS, et al. Interactive coronary MRI. Magn Reson Med. 1998;40:105-11.

28. Pennell DJ, Bogren HG, Keegan J, Firmin DN, Underwood SR. Assessment of coronary artery stenosis by magnetic resonance imaging. Heart. 1996;75:127-33.

29. White RD, Pflugfelder PW, Lipton MJ, Higgins CB. Coronary artery bypass grafts: evaluation of patency with cine MR imaging. AJR Am J Roentgenol. 1988;150:1271-4.
30. Rubinstein RI, Askenase AD, Thickman D, Feldman MS, Agarwal JB, Helfant RH. Magnetic resonance imaging to evaluate patency of aortocoronary bypass grafts. Circulation. 1987;76:786-91.

31. Aurigemma GP, Reichek N, Axel L, Schiebler M, Harris C, Kressel HY. Noninvasive determination of coronary artery bypass graft patency by cine magnetic resonance imaging. Circulation. 1989;80: 1595-602.

32. Langerak SE, Vliegen HW, de Roos A, Zwinderman AH, Jukema JW, Kunz P, et al. Detection of vein graft disease using highresolution magnetic resonance angiography. Circulation. 2002;105: 328-33.

\section{Bound volumes available to subscribers}

Bound volumes of The Journal of Thoracic and Cardiovascular Surgery are available to subscribers (only) for the 2005 issues from the Publisher, at a cost of $\$ 134.00$ for domestic, $\$ 165.85$ for Canadian, and $\$ 155.00$ for international subscribers for Vol 129 (January-June) and Vol 130 (July-December). Shipping charges are included. Each bound volume contains a subject and author index.

The binding is durable buckram with the Journal name, volume number, and year stamped in gold on the spine. Payment must accompany all orders. Contact Elsevier Inc., Subscription Customer Service, 6277 Sea Harbor Dr, Orlando, FL 32887, USA; phone 800-654-2452 or 407-345-4000.

Subscriptions must be in force to qualify. Bound volumes are not available in place of a regular Journal subscription. 